\title{
ALGUNAS FUENTES DE QUEVEDO
}

\section{LOS HEREJES DEL SUEÑO DEL INFIERNO}

Un estudio sistemático del problema de la herejía en España -problema, por lo demás, tan apasionante para toda la Europa de entonces- contribuiría no poco a la comprensión del pensamiento de Quevedo. En este estudio sólo nos referiremos a un aspecto muy determinado de la obra del escritor español: la larga lista de herejes que aparece al final del Sueño del infierno, con particular atención a las fuentes utilizadas y a su tratamiento.

Por lo pronto es fácil ver que el pensamiento de la época, aun fuera de España, fluctúa entre dos nociones bien distintas de herejía. Una, la más generalizada, entiende por tal toda creencia (religiosa o no) en disonancia con el dogma (o con las opiniones dogmáticas más recibidas), sea ella anterior o posterior al cristianismo. Así por ejemplo, en el Catalogus haereticorum de Petreius, compuesto a principios del siglo xvn, se incluyen títulos de este tenor: "Mathematici (et nunc et olim)", "Samaritani", "Judaeorum secta", etc. Se hallan también en él algunas religiones antiguas, como los "Musca-Accaronitae" (antiguo culto de Ecrón, mencionado en el primer capítulo de II Reyes). Petreius llega, inclusive, a nombrar entre los herejes a los maronitas, no obstante haberse sometido éstos al papado ya en $1182^{1}$. El catálogo heresiológico más importante de los siglos xvr y xvir es tal vez el Adversus omnes haereses del español Alfonso de Castro $\left(1495^{-1} 5^{88}\right)^{2}$. Al principio del volumen se nos da la definición: "Haeresis est dogma falsum, fidei orthodoxae re. pugnans". $\mathrm{Y}$, de acuerdo con estos términos amplios, se menciona

1 Theodorus Perreius (nombre latinizado del cartujo Theodor Peeters), Catalogus haereticorum et haeresiarcarum (Colonia, 1629, por Pedro Brachel).

2 Alfonsus de Castro, Adversus omnes haereses libri quatordecim (tengo a la vista la edición de $155^{8}$, Colonia, por Juan Novesiano). Hablando de heresiólogos españoles, diremos que en el Para todos de Montalbán (1632) sc atribuye a Quevedo la composición de un tratado sobre esta materia: "Don Francisco Gómez de Queuedo Villegas, Cauallero del Ábito de Santiago..., tiene para sacar a luz... Origen de todas las heregias, y Fisionomia para conocer los Nouatores que preuienen persecución contra la Iglesia" (Para todos, ed. de Alcalá, 1661, p. 519). 
entre los herejes a idólatras o apóstatas del Antiguo Testamento ("Musoritae", "Heliognostici", etc.).

El otro concepto de herejía que existía en tiempos de Quevedo es más estricto, aunque menos generalizado. Se trataba, en principio, de la noción moderna, sostenida ya por teólogos salmantinos del siglo xvi. Según ella, no es hereje nadie que no haya recibido el bautismo. Tal es la definición de Melchor Cano (Loci theologici, bajo el título "De haeresi"), que concuerda con el concepto tomista: "Ideo haeresis est infidelitatis species, pertinens ad eos qui fidem Christi profitentur, sed ejus dogmata corrumpunt"3.

La tesis de Suárez es todavía más radical. Sólo son herejes los que sustentan errores en contra de la verdad revelada formal, no sólo virtualmente (o simplemente proclamada por la Iglesia, como la transubstanciación $)^{4}$. En suma, según este concepto más moderno, que ya comenzaba a ser elaborado en tiempos de Quevedo, y aun antes, los herejes no deben confundirse ni con los idólatras del Antiguo Testamento ("apóstatas", si antes habían profesado la religión monoteísta), ni menos aún con los cismáticos (la mayoría de los cultos cristianos orientales) que, aunque no sometidos a la autoridad papal, no disienten en ningún artículo de fe divinamente revelado (o tenido por tal).

De esta consideración preliminar resulta que Quevedo no se atuvo al concepto más riguroso de herejía, sino, evidentemente, a la noción amplia. En el Sueño del infierno menciona veintitrés "herejías" del Antiguo Testamento ${ }^{5}$ y, entre los herejes posteriores, a Mahoma".

En la edición de la $B A A E E$, al principio de la lista de herejes del Sueño del infierno, Fernández Guerra inserta la siguiente nota: "Quevedo, para estos argüidos de herejes antes de la venida de Cristo, no hizo sino compilar el Catálogo de las herejias formado por Filastrio, obispo de Brescia, varón doctísimo en las Sagradas Escrituras, amigo y familiar de San Ambrosio de Milán, y que floreció en el imperio de Teodosio, por los años de $3^{80}$. Philastrii episcopi brixiensis haereseon catalogus (Basilea, 1528, sin noticia de impresor, que debe de ser Juan de Fabro)"'?.

s Tomás de Aquino, Summa theologica, IIa IIae, q. x, a. 1.

- Francisco SuÁrez, De fide, disp. III, sect. xi, n. 11.

- Sólo después de haber concluido este artículo llega a mis manos la excelente edición critica y sinóptica del Sueño del infierno por Amédée Mas (Poitiers, 1955). La serie completa de herejes anteriores a Cristo falta en todos los manuscritos utlizados por Mas, aunque está en las ediciones impresas.

" Recordemos, sin embargo, que según una antigua tradición Mahoma había apostatado de la fe cristiana. Cf. la nota de C. II. Grandgent en el argumento del Canto XXVIII del Inferno, en su ed. de la Divina Commedia, Cambridge, Mass., 1933, p. 247 .

7 Me he visto forzado a depender, para este artículo, de la ya centenaria 
La nota de Fernández Guerra es correcta, en lo esencial, peıo I) la edición príncipe de Filastrio (Basilea, $15^{28}$ ) no es de Juan de Fabro, sino de Juan Sichard (Joannes Sichardus) ${ }^{8}$; 2) Quevedo pudo haber utilizado tanto la edición príncipe como la segunda, también de Basilea (1539); 3) según Fernández Guerra, Quevedo se basó en Filastrio para los herejes del Antiguo Testamento: en realidad, Quevedo siguió al mismo heresiólogo también para nueve personajes posteriores; 4) dice el mencionado editor que Filastrio fue "varón doctísimo en las Sagradas Escrituras": ello tampoco es seguro (como en seguida veremos). De la vida del heresiólogo de Brescia poco se sabe (aun su nombre ofrece dificultad, pues, aunque las grafías con $P h$ fueron rechazadas por los eruditos, compiten los nominativos Filastrius y Filaster en los manuscritos). ${ }^{9}$. Casi todos los datos biográficos que de él se poseen provienen de un sermón de su sucesor, San Gaudencio, con motivo del décimoquinto aniversario de su muerte ${ }^{10}$. El Liber de haeresibus de Filastrio contiene una rápida exposición de las opiniones heterodoxas, tanto judías como cristianas, hasta la época del autor. Enumera 28 "herejías" judaicas y 128 cristianas. La segunda parte puede dividirse en dos secciones, de 64 herejías cada una. En la primera, las opiniones son estudiadas históricamente y atribuidas a un autor. En la segunda, se las agrupa según sus enseñanzas, repitiéndose muchas sectas ya mencionadas en la primera. Las cifras 28 y 128 son, pués, arbitrarias. Filastrio quiso atenerse a ellas, como dice G. Barry (loc. cit.), aun a riesgo de multiplicar innecesariamente herejes $y$ herejías. Y, acerca del Liber de haeresibus, añade:

No tiene sino un débil valor doctrinal. En ninguna parte se preocupa el autor de definir el concepto mismo de herejía, y llega a

edición de Fernández Guerra (BAAEE, t. 23, pp. 321-324). La reedición de Clás. cast. (1916) no es más que una reproducción puntual y pedestre del texto y las notas de Fernández Guerra, atribuidos esta vez a Julio Cejador y Frauca. Las llamadas "ediciones críticas" de Astrana Marín (a pesar de su contribución positiva, en lo relativo a la exhumación de algunos documentos inéditos) jamás justifican sus variantes, carecen casi por completo de aparato textual, y en este pasaje, por ejemplo, no dicen una palabra sobre los herejes mencionados por Quevedo o las fuentes utilizadas. En cuanto a la excelente edición crítica y sinóptica de Amédée Mas, repito que no tuve ocasión de verla oportunamente.

${ }^{8}$ Albertus Fabricius, a quien se debe la $5^{*}$ ed. de Filastrio (Hamburgo, 1721 ), dice que la edición príncipe es de E. Petrus; pero G. Bardy (Dictionnaire de théologie catholique, $s, v$, "Philastre") y sobre todo F. MARx, en su excelente edición crítica (FILAstri Diversarum haeveseon liber, Vindobonae, 1898 , Corpus scriptorum ecclesiasticorum latinorum, 38), p. xxvii, la atribuyen a Joannes Sichardus (Jean Sichard). Marx describe la edición príncipe detenidamente.

-Véase F. MARx, ed. cit., p. viii, "De nomine Filastrii et patria".

${ }^{10}$ Reproducido en varias ediciones de Filastrio y en la $P L$, t. 22, cols. 997- 
incluir bajo ese nombre opiniones que nada tienen de erróneo, como: Alia est haeresis quae terrae motum non Dei jussione et indignatione fieri, sed natura ipsa elementorum opinatur (cn)... Sobre todo en la última parte de la obra, se multiplican noticias de tal género. Hoy nos sería imposible asignar nombres o fechas a los errores, reales o imaginarios, que Filastrio describe.

Esta última afirmación es interesante para nuestro estudio. A ello se debe tal vez que Quevedo, después de seguir fielmente el Liber de Filastrio, lo deje de pronto y siga con otra fuente. Claro es que no podría haberse servido de "herejías" del tenor de la siguiente: Alia est haeresis, quae dicit incertum numerum esse annorum a mundi origine (cx).

Las primeras 32 herejías enumeradas en el Sueño del infierno están tomadas del texto de Filastrio, y casi exactamente en el mis. mo orden:

FiLASTRIO

1. Ophitae

2. Caiani

3. Sethiani

4. Dositheus

5. Sadducaei

6. Pharisei

7. Samaritani

8. Nazarei

9. Esseni

10. Heliognosti

11. Ranarum cultores

12. Musoritae

13. Musca-Accaronitae

14. Trogloditae

15. Fortuna Coeli

16. Bahalitae

17. Astharitae

18. Haeresis de idolo Moloch et Remphan

19. Haeresis de ara Tophet

20. Puteoritae
Quevedo

ofiteos

cainanos

sethianos

Dositheo

Saddoc, autor de los sadduceos

fariseos

heliognósticos devictíacos

los que veneran las ranas

musoritos

los que adoran la Mosca accaronita trogloditas

los de la fortuna del cielo

los de Bahal

los de Asthar

los del ídolo Moloch y Renfán

los del ara de Tofet

puteoritas

1002. El discurso de Gaudencio presenta a Filastrio como viajero incansable, que recorrió el mundo romano para predicar la Palabra de Dios y contender con paganos, judíos y heterodoxos. Sus principales adversarios fueron los arrianos. Durante su permanencia en Milán, donde disputó con el arriano Auxencio, se relacionó con San Agustín (que lo menciona en su Epistola 222). $\mathrm{Su}$ elevación al episcopado, de fecha incierta, debió de ser anterior al $3^{81}$, año en que aparece entre los obispos del Concilio de Aquilea (PL, t. 12, col. 1061). 
21. Haeresis ob aeneum serpen- los de la serpiente de metal tem

22. Haeresis subterraneis in locis ad omnem turpidinem apta

23. Haeresis cum Thamur simulachro

las judías... que lloraban a Thamur en su simulacro

24. Belitae

25. Haeresis cum Bahal idolo

bahalitas

26. De Pythonissa muliere haeresis superstitiosa

27. De Asthar et Astharot simu- los de Astar y Astarot lachris haeresis

28. Herodiani herodianos

Catalogus eorum qui post Christi passionem haereseos arguuntur

29. Simon Magus

3o. Menandrus

31. Saturninus

32. Basilides

33. Nicholavs Antiochenus

34. Haeresis ab luda traditore

35. Carpocras

36. Cerinthus

37. Hebion

38. Valentinus
Simón el Mago

Menandro

Saturnino

Basilides

Nicolás antioqueño

(En varios lugares de la obra de Quevedo, pero no aqui)

Carpócrates

Cerinto

Ebión

Valentino

Nótese con cuánta fidelidad sigue Quevedo el orden de Filastrio. Pero hay algunas omisiones. Acaso los samaritanos (pueblo más bien que secta) se omiten porque su nombre recordaba la parábola del buen samaritano. Los "nazareos" no eran en realidad herejes, sino los que se consagraban con voto especial a Jehová en el Antiguo Testamento (Números, 6). Su nombre, además, se parece a "Nazareno", nombre dado a Jesús y a los primitivos cristianos (Hechos, 24:5). Los esenios se omiten tal vez porque de ellos dice Filastrio: "Monachorum vitam exercent, escas delitiosas non sumentes, nec studium in vestimentis gerentes, nec possidentes aliquid: lectioni autem et bonis operibus insistentes..." En cuanto a la herejía del número 34, "Haeresis ab Juda traditore", Quevedo no la incluye en esta lista, pero la menciona unas páginas antes, en el mismo Sueño del infierno:

Llegándome cerca [de Judas] le dije: “¿Cómo, traidor infame sobre todos los hombres, vendiste a tu Maestro, a tu Señor y a tu Dios por tan poco dinero?" A lo cual respondió: "Pues vosotros, ¿por qué os quejáis deso? Que sobrado bien os estuvo, pues fue el medio y arcaduz para vuestra salud. Yo soy el que me he de quejar, 
y fue a mí a quien le estuvo mal, y ha habido herejes que me han tenido veneración, porque di principio en la entrega a la medicina de vuestro mal"11.

Quevedo debió de obtener esta última información del mencionado título 34 de Filastrio: "Alii autem a Juda traditore instituerunt haeresim dicentes: bonum opus fecisse Judam, quod tradiderit Salvatorem. Hic enim, inquiunt, nobis omnis scientiae bonae autor [sic] extitit... Hoc sciens Juda, quod si fuerit passus Christus, salutem hominibus allaturus esset, hinc tradidit Salvatorem".

Las paradojas "Judas instrumento de salvación" y "Judas menos culpable que los herejes" parecen haber sido una idea fija de Quevedo. En el Sueño de las calaveras hace decir al traidor: "Señor, yo soy Judas, y bien conocéis vos que soy mucho mejor que éstos [Mahoma y Lutero]: porque, si os vendí, remedié al mundo, y éstos, vendiéndose a sí y a vos, lo han destruido todo" ${ }^{12}$.

Veamos ahora cómo elabora Quevedo la fuente latina. Comparemos la primera herejía de su lista con la primera de Filastrio.

Estaban los ofiteos, que se llaman así en griego de la serpiente que engañó a Eva, la cual veneraron a causa de que supiéramos el bien y el mal.
Primi sunt Ophitae, qui dicun. tur Serpentini, isti colubrum venerantur dicentes: quod hic prior initium nobis sapientiae boni $c t$ mali attulerit.

(Serpentini es traducción latina del helenismo ophitae. La españolización ofteos puede ser forma analógica: cf. saduceos, fariseos, etc.). Aquí Filastrio comete un anacronismo, y Quevedo también, por supuesto, dando pruebas de poca solidez en su cultura patrística. Los ofitas no fueron una secta judaica anterior a la venida de Cristo, sino gnósticos del siglo $n$, probablemente derivados de la escuela de Valentino (a quien Quevedo menciona más adelante). Las principales referencias antiguas a los ofitas se hallan en Orígenes, Ireneo, Teodoreto, Tertuliano, Epifanio y San Agustín ${ }^{13}$, y todos ellos los dan como gnósticos del siglo n. Pero no sólo los ofitas: también los cainanos y los setianos fueron gnósticos de ese siglo:

...los cainanos, que alabaron a Cain porque, como decían, siendo hijo del mal prevaleció su mayor fuerza contra Abel.
Caiani, qui Cain laudant... dicentes ex altera virtute, id est diaboli, Cain factum, ex altera autem Abel... et virtutem majorem, quae erat in ipso Cain invaluisse.

${ }^{11}$ Ed. cit., p. 316, en nota al pie. En la reimpresión de Clas. cast., pp. $143^{-144}$.

${ }_{12}$ Clás. cast., p. 5o. En la ed. original de Fernández Guerra, p. 301.

13 Orígenes, Contra Celsum, VI, 24-29; Tertuliano, De praescr. haeret, 47; Epifanio, Haer., 37, 3 ss.; Teodoreto, Haeret. fab., I, 14; Agustín, De haeres. ad Quodvultdeum. El testimonio más antiguo conservado es el de IRENeO, Adversus haereses ( $P G, \mathrm{t} .7$, cols. 694-704). 
Creo que la forma Caiani era la más común en latín, aunque existían otras ${ }^{14}$. Quevedo la traduce cainanos (derivado más natural de Caín). La secta cainana fue, precisamente, la que reverenció a Judas como el instrumento por cuyo medio pudo consumarse el sacrificio expiatorio de Cristo. Esto no lo consigna Filastrio (que, bajo dos títulos distintos, se refiere a los cainanos y a la herejía del traidor Judas). Producción de los cainanos fue el Evangelio apócrifo de Judas, del cual cita Ireneo este interesantísimo pasaje: "Judas, siendo el único que conoció la verdad antes que los otros, consumó el misterio de la entrega"1".

Quevedo no debió de tener un conocimiento directo de estos pasajes patrísticos, pues no sólo no relaciona a los cainanos con los herejes que veneraban a Judas (mencionados repetidamente en los Sueños), sino que incurre en el citado anacronismo.

No podemos seguir con la comparación de textos para cada uno de los peronajes. En suma, Quevedo toma toda su información del heresiólogo antiguo, sin añadir datos nuevos; sólo intercala un chiste (a propósito de los "musoritas") o una digresión moral (des. pués de mencionar a Dositeo), etc. He aquí, sin embargo, algunas observaciones sueltas:

Número ro de Filastrio: Quevedo escribe heliognósticos en lugar de heliognostos (que se esperaría del latín heliognosti). Sin embargo, heliognostici, que no aparece en Filastrio, era más común, y se halla en Petreius y en otros tratados heresiológicos de tiempos de Quevedo ${ }^{16}$.

Número 12: los musoritos no fueron una secta herética, ni siquiera una religión antigua. De ellos dice Filastrio: "Admoniti a suis aureos fecerunt mures, atque eos cum arca et sedibus aureis remiserunt" ${ }^{17}$. Petreius también los cita, refiriéndose a Filastrio como única fuente.

1.4 La forma Caiani se halla también en Petreius, op. cit., p. 39. Es evidente que corresponde al griego Kaıayoi, que hallamos en Ireneo (Adv. haer., I, 35). Deriva Kacavoí del nominativo Kaís, en que la nasal del tema cae ante sigma. En el pseudo-Tertuliano hallamos Caiana haeresis (Adv. omnes haereses, 33). En el mencionado capítulo 47 de Tertuliano, De praescr. haereticorum, hallamos otras dos formas menos usadas: Cainai y Cainiani.

${ }^{1 s}$ El original griego de este pasaje de Ireneo se perdió, y sólo se conserva en traducción latina (igual que los libros II a $\mathrm{V}$ de Adversus haereses y la parte final del primer libro). Tengo a la vista la excelente edición de $A$. Stieren, Lipsiae, 1853 , p. 274: "Et haec Iudam proditorem diligenter cognovisse dicunt [Caiani], et solum prae ceteris cognoscentem veritatem, praefecisse proditionis mysterium; per quem et terrena et caelestia omnia dissoluta dicunt. Et confictionem afferunt huiusmodi, Iudae evangelium illud vocantes". En notas al pie el editor reproduce los correspondientes textos griegos de Teodoreto y Epifanio. Entre esos pasajes griegos hay uno (EPIFAnio, IIaer., 38) que es, sin duda, la fuente directa de Filastrio.-Como expresión literaria de este tema heresiológico, véase el cuento de Borges, "Tres versiones de Judas".

1s Petreius, op. cit.; G. Prateolus (Dupréau), De vitis, sectis et dogmatibus omnium haereticorum (Colonia, 1581 ).

${ }^{17}$ Filastrio se basa aquí en el episodio de I Samuel (I Reyes en la Vul- 
Número 20: los puteoritas, igual que los "trogloditas" (núm. 14), son herejías imaginarias del obispo de Brescia, como anota Fernández Guerra. Filastrio toma aquí ingenua y literalmente el apóstrofe metafórico de Jeremías, 2:19: "Porque dos males hizo mi pueblo: me dejaron a mí, fuente de agua viva, y cavaron para sí cisternas, cisternas rotas que no detienen agua"18.

Número 23, "Haeresis cum Thamur simulachro": Fernández Guerra, basándose sólo en el texto de Filastrio, anota (y Cejador copia): "Thamur es el mismo faraón, rey de Egipto en los tiempos de Moisés". El Liber de haeresibus dice: "Thamur enim Pharao ille dicebatur Rex Egyptiorum, qui sub beato Mose Egyptis praesidebat illo tempore". La cita bíblica, que Fernández Guerra no da, es Ezequiel, 8:13-14: "Y me dijo: Vuélvete y verás mayores abominaciones que hacen. Y me volví a la puerta de la verja de la casa de Dios, y he aquí había mujeres sentadas llorando por Thamuz". La letra final de esta palabra hebrea es zayin, no resh. La forma Thamur, en lugar de Thamuz, es error de la edición príncipe de Filastrio (1528), como también de las tres ediciones siguientes $(1539,1611 \text { y } 1621)^{19}$. Filastrio, como hemos visto, supone que Thamuz fue el faraón de tiempos de Moisés ${ }^{20}$. Fabricio, en su edición de Filastrio de 1721 (ad locum), cita un pasaje de Diodoro Sículo en

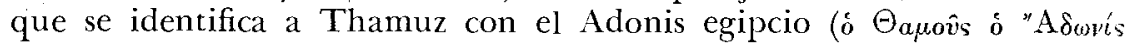

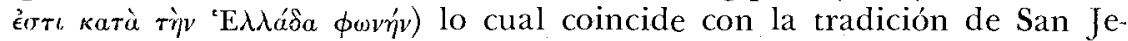
rónimo ${ }^{21}$; pero los exégetas de Ezequiel, 8:14 tienen también otras

gata y los Setenta), 6:4-5. Los filisteos habian tomado en batalla el arca del pacto de Israel. Mas habiéndoles enviado Jehová una plaga, por consejo de sus sacerdotes la devolvieron con presentes: ratones de oro e imágenes recordatorias del castigo divino.

${ }^{18}$ El mismo Filastrio cita el texto latino: "Me dereliquerunt, fontem aquae vivae, et foderunt sibi lacus detritos, qui non possunt capere aquam". Esta exégesis de los lacus detritos de Jeremías, junto con otros detalles ya referidos, nos hacen dudar de que Filastrio fuera "varón doctísimo en las Sagradas Escrituras", como anota Fernández Guerra, y como copia a la letra Cejador.

${ }^{19}$ Ninguno de los mss. estudiados en la edición de F. Marx tiene la forma incorrecta Thamur por Thamuz, o, a lo menos, Marx no lo consigna (p. 1o). Pero la edición príncipe se basó en un códice hoy perdido (pp. xxviixxviii). Sea que Thamur proviniera o no de alguno de los manuscritos perdidos, no hay duda de que es error. Pero no creo que el texto de Quevedo deba enmendarse. El escritor español leyó Thamur en la edición primitiva, y sin duda lo trasladó así a su manuscrito.

${ }^{20}$ Por cálculos basados en las cronologías bíblica y de Egipto, se acepta generalmente que el faraón de la opresión fue Ramsés II, y el del éxodo Meremptah, ambos de la XIX dinastía, aunque un descubrimiento arqueológico reciente parece debilitar esa teoría. Cf. T. CHeYne, Encyclopaedia Biblica, London, 1902, s. $\circlearrowright$. "Pharao". De todos modos, la arqueología bíblica no conoce ningún Thamuz en tiempos de Moisés.

${ }^{21}$ En este lugar explica San Jerónimo: "Adonidem, qui occisus et revixisse narratur: Junium mensem eodem appellant nomine, et anniversaria ei celebrant solemnitatem" (citado por Clarius en Critici sacri, Londres, 1660, vol. V, "Annotata ad Ezechielem", p. 39; en el mismo lugar puede verse una serie de comentarios antiguos sobre Thamuz). 
hipótesis ${ }^{22}$. Platón y Filóstrato parecen identificar a Thamuz con un faraón legendario ${ }^{23}$. Por lo menos una cosa es segura: que la forma Thamur por Thamuz en las primeras ediciones de Filastrio es errata de imprenta.

Nümero 26, "De Pythonissa muliere haeresis superstitiosa". El texto de Filastrio (ed. príncipe) trae en nota la referencia bíblica, que Fernández Guerra omite. Se trata de la pitonisa de Endor, de I Samuel, 28. Dice el heresiólogo: "Alia est haeresis de Pythonissa, qua cooperientes vestimentis mulierem, ab ea quaedam responsa sperabant posse consequi: unde et aiunt Pythonissam illam beati Samuelis animam ab inferís excitasse..." Es evidente que al decir: "cooperientes vestimentis mulierem" Filastrio recuerda mal el pasaje bíblico, que dice del rey Saúl: "Cooperivit se et, mutatis vestimentis, alium se simulavit". En cuanto al extraño epíteto que da Quevedo a la pitonisa, "arremangada", se debe probablemente a la interpretación contrario sensu de "cooperientes" (arremangada significaría lo contrario del participio de cooperio).

Número 29, Simón el Mago. La leyenda del vuelo de Simón, que Fernández Guerra ingenuamente da por histórica, proviene del libro apócrifo de los Hechos de Pedro ${ }^{24}$. Desde los tiempos de Justino Mártir, Simón el Mago fue objeto de abundante literatura patrística, no obstante lo cual es, sin duda, el personaje más complicado de toda la heresiología primitiva ${ }^{25}$. Quevedo tomó a este personaje del título 29 de Filastrio, pero la nota de Fernández Guerra (copiada con puntos y comas por Cejador) proviene de las Officinae de Ravisio Textor ${ }^{26}$. La

${ }^{22}$ Cherne, op. cit., t. 4, col. 4893, deriva Thamuz del nombre babilónico Dumuzi, y cita en nota al pie varios estudios modernos que, contra las explicaciones tradicionales de Ezequiel, 8:14, identifican este nombre con una deidad asirio-babilónica, no egipcia.

${ }_{28}$ Filóstrato, Opera quae supersunt omnia, Lipsiae, apud T. Fritsch, 17og, p. 234: "Thamum enim res novas olim apud Memphitas molientem, increpavere Gymnosophistae et coercuere..." El editor G. Olearius anota: "Thamoûn est ex antiquissimis Egypti regibus cuius Plato meminit in Phaedro. Eum ab hippopotamo discerptum periisse narrat Syncellus p. 54. Unde quae de planctu Thamous apud Ezechielem prophetam sunt, nonnulli explicant, quem Osiridem vel Adonidem putant". En el referido pasaje del Fedro, Platón pone en boca

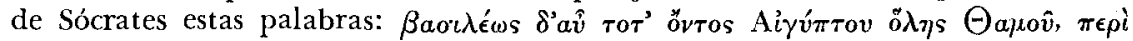

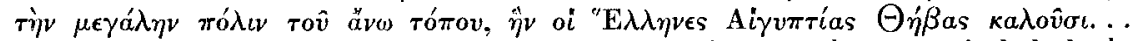
("siendo entonces rey de todo Egipto Thamús, junto a la gran ciudad de la región superior que los griegos llaman Tebas egipcia..." (Platonis. . Phaedrus, ed. I. C. Vollgraff, Lyon, 1912, p. 91).

${ }^{24}$ Apócrifo que parece de origen oriental. Cf. L. Vouaux, Les actes de Pierre. Introduction, textes, traduction et commentaires, Paris, 1922. La leyenda del vuelo de Simón está en el cap. 31 .

${ }_{25}^{25}$ tal punto, que se ha creído que el Simón del Nuevo Testamento y el de los relatos patrísticos son dos personajes distintos. Cf. Hechos, 8:9-13, 18-24, frente a IrEneo, Adversus haereses 1, 22, 2; Hegesipo, en Eusebio, Historia ecclesiastica, III, 4, 13, y Tertuliano, De anima, 34. H. A. Wolfson, The philosophy of the Church Fathers, Harvard University Press, 1956, pp. $5^{12}$ ss., incluye otras referencias patrísticas y un estudio del sistema de Simón.

$\because$ De estas Officinae he visto una edición de L. Junta (Venecia, 1537); otra 
explicación: "En Roma, imperando Claudio, logró ser tenido por Dios, y dicen que honrado con aras y sacrificios" (Fernández Guerra) corresponde a Textor: "multos elusit Romae imperante Claudio principe, ita ut numinis loco habitus sit, et honore simulachri decoratus, cum hac inscriptione: Simoni Deo Sancto"2t.

Número $3^{\circ}$, Menandro. Aquí también la nota de Fernández Guerra ("Menandro, mago también de Samaria y discípulo de Simón, hizo por que le creyesen el salvador bajado del Olympo para salud de los hombres... Enseñaba que no se podía vencer a los ángeles con ningún pacto, sino con los recursos de la magia") se basa en Textor: "Menander magus, genere Samaritanus, servatorem se vocabat ex Olympo ad hominum salutem demissum. Docebat nullo pacto angelos ab hominibus vinci posse quam magicae artis disciplina".

Número 38 : Valentino es el último de los herejes que Quevedo toma directamente de Filastrio. "El que dio por principio de todo el mar y el silencio" corresponde a la explicación del Liber de haeresibus: "... Coepit hoc definire: Nihil erat aliud ante, inquit, in mundo, nisi profundum maris et silentium". Valentino es el primer personaje mencionado en el importante tratado Adversus haereses de San Ireneo de Lyon (el principal heresiólogo antiguo). Según Ireneo, Valentino dio por principio de todo a Bythos y al silencio ${ }^{28}$.

Quevedo ha ido siguiendo hasta aquí el Liber de haeresibus, pero no lo cita. Mencionará a su autor, sin embargo, años más tarde, en una de sus obras serias, en que no lo utiliza como fuente: Las cuatro pestes y las cuatro fantasmas ${ }^{29}$.

El lector que compare la parte final del Sueño del infierno con una edición moderna de Filastrio (la de F. Marx, por ejemplo) notará que Quevedo sigue fielmente al heresiólogo antiguo hasta Valentino, el noveno hereje posterior a la venida de Cristo. Luego, a partir de Menandro (a quien menciona ahora por segunda vez), sigue otra fuente.

Esta segunda fuente es un Suplemento de Filastrio, añadido a las primeras ediciones, y del que Quevedo toma nueve nombres:

"Apud Milochum, Venetiis, 1537", y una reedición posterior también de Venecia: Antonius Julianus, 1617 .

${ }^{27}$ El relato de la estatua con la inscripción Simoni deo sancto se halla primero en Justino Mártir, I $A p o l$, 26, y lo repiten sucesivamente Ireneo, Adv. haer., I, 23, 4, Tertuliano, Apol., 23, y Eusebio de Cesárea, Hist. eccles., II, 23. Se lo tuvo por histórico hasta que, en 1574, se excavó (en la misma isla del Tíber mencionada por Justino) una columna votiva con la inscripción Semoni Sanco deo fidio sacrum, esto es, consagrada a la deidad sabina Semo Sancus, lo cual indicaría que Justino leyó mal la inscripción. Sin embargo, Fernández Guerra repite esta historia desechada ya por historiadores del siglo Xvi (y Cejador lo copia).

${ }^{28}$ En antiguos testimonios heresiológicos sobre Valentino se basa la monografía de G. Heinrici, Die Valentinianische Gnosis und die heilige Schrift. Eine Studie, Berlin, 1871 .

${ }^{20}$ Ed. Fernández Guerra, BAAEE, t. 48, p. 115 . 
Menandro, el mozo de Samaria (mencionado por segunda vez); Montano el frigio; Priscilla y Maximilla, seguidoras de aquél; Nepos; Sabino, prelado arriano; los templarios; Guillermo, "el hipócrita de Anvers"; y Bárbara, mujer del emperador Segismundo.

Aparece este Supplementum incerti scriptoris en la edición príncipe de Filastrio (Basilea, 1528), así como en la segunda (Basilea, 1539), y en la tercera y cuarta, de Helmstadt, 1611 y 1621 . Albertus Fabricius, en su edición de Hamburgo, 1721, omite el Supplementum -y a partir de él lo harán también las ediciones modernasdando esta razón en el prólogo $A d$ lectorem (p. 4): "Caeterum appendicem sive supplementum recentis scriptoris, cum parum accuratum sit, nullius auctoritatis, praetermissi". Resolución acertada porque, en efecto, el "apéndice o suplemento de autor reciente" da la impresión de ser poco exacto (como veremos en seguida) y "de ninguna autoridad". Consiste en una rápida enumeración de 73 herejías, algunas de las cuales ya estaban en Filastrio. Cubre unas quince páginas. En muchos casos, este Supplementum no hace sino reproducir fielmente el catálogo de herejes que aparecía ya en las Officinae de Ravisio Textor, pero incluye también algunos nombres que faltan en éste. Según Fernández Guerra, “para los herejes posteriores a la venida de Jesucristo se valió Quevedo..., además del índice de Filastrio, de los católogos de Juan Ravisio Textor: Joannis Ravisii Textoris Officinae, Lugduni, ${ }^{1585}$, t. II"'30. Sin embargo, Quevedo no necesitó valerse de la obra de Textor. Entre los herejes del Sueño del infierno no hay ninguno que esté en las Offrcinae y que falte en Filastrio o en su Suplemento. Por el contrario, hay un título (Guillermo "el hipócrita de Anvers") en que Quevedo coincide con el Supplementum, pero que falta en Ravisio Textor ${ }^{31}$.

El primer personaje que Quevedo toma del Suplemento es Menandro (título 19), sin notar que ya lo había tomado antes del mismo texto de Filastrio (título 3o):

\section{Sueño del infierno}

Menandro, el mozo de Samaria, decía que él era el Salvador y que había caído del cielo.

\section{Supplementum}

Menander Magus, genere Samaritanus, servatorem se vocabat ex Olympo ad hominum salutem demissum.

${ }^{30}$ Las Officinae y otras obras de Ravisio, hoy olvidadas, alcanzaron gran número de reimpresiones hasta fines del siglo xvn, y sirvieron, directa $o$ indirectamente, como obra de consulta a más de un escritor español de la época. Jean Tixier (Joannes Ravisius Textor), señor de Ravissy, nació en 1480. Fue elegido rector de la Sorbona en 1520, y murió prematuramente en 1524 .

${ }^{31}$ Amédée Mas, basándose sólo en las dos fuentes indicadas por Fernández Guerra (Filastrio y Textor), llega a la conclusión inexacta de que Quevedo sacó de su propia cosecha los títulos "Nepos", "Guillermo" y "los templarios" 
Este título del Suplemento está copiado del catálogo de herejes de las Officinae de Textor. Para los tres personajes que siguen, Quevedo se basa en el título 21, "Montanus"32, del Supplementum:

Menandro. .. decía que él era el Salvador..., y por imitarlo decía detrás de él Montano frigio que él era el Parácleto. Síguenles las desdichadas Priscilla y Maximilla heresiarcas. Llamáronse sus secuaces catafriges, y llegaron a tanta locura, que decían que en ellos, y no en los apóstoles vino el Espíritu Santo.
Montanus Phryx natione, vocabat se Paracletum. Multos in suam traxit haeresim. Et Priscam et Maximillam, quae eo redigit insaniae, ut relictis viris eum sequerentur, ejusque inspiratione Spiritum Propheticum habere se crederent. Sectatores ejus Cataphryges dicuntur. Hi Spiritum Sanctum sibi, non Apostolis, infusum praedicabant.

También aquí el Supplementum coincide a la letra con Textor.

Nepos, el personaje que sigue, está tomado del título 24 del Suplemento, aunque después reaparece en el mismo Suplemento bajo el título 72. El pasaje de Quevedo: "Estaba Nepos, obispo... afirmando que los santos habian de reinar con Cristo en la tierra mil años en lascivias y regalos" corresponde muy de cerca al latín: "Dicebat sanctos in terra cum Christo mille annis in delitiis regnaturos". La atribución a Nepos de un milenio carnal y grosero tiene su fuente última en el testimonio de Cayo, conservado por Eusebio de Cesárea (Historia eclesiástica, III, 28). Aunque presentado aquí como hereje, parece haber sido en general ortodoxo (poco acertada es la comparación con Cerinto, en la nota de la $B A A E E$ ). Hasta en el Catálogo de Petreius (por no citar obras modernas) leemos: "Millenariorum sententia fuit a magnis viris asserta, et tunc nondum satis ab Ecclesia proscripta” (bajo el título “Nepos") ${ }^{33}$.

El personaje que sigue es de interés especial:

Venía luego Sabino, prelado hereje arriano, el que en el Concilio Niceno llamó idiotas a los que no seguían a Arrio.
Sabinus praesul Heracleae, secta fuit Arrianus. Is Christianos omnes (qui in Synodo Nicena ab Arrio defecerant) idiotas vocabat et ignavos, eosque infirmitate ingenii lapsos dicebat.

(ed. cit., Apéndice VI). Nepos y los templarios debieron de escapársele a Mas por inadvertencia, pues ambos títulos están en las ediciones de Textor que he podido consultar. En cuanto a Guillermo de Amberes, falta en las ediciones de Textor que he visto, pero está en el Supplementum Filastrii.

${ }^{32}$ Las acusaciones tradicionales contra Montano (de que Fernández Guerra se hace eco en su nota) han sido revisadas del todo modernamente por eruditos católicos y protestantes. Ver diccionarios teológicos e historias eclesiásticas.

"3 La doctrina de los quiliastas o milenarii (que agitó vivamente la Iglesia de los tres primeros siglos) tiene su base neotestamentaria en el Apocalipsis, 20. Entre los padres apostólicos la mantuvo Papias (conservado por EusEbio, $o p$. cit., VII, 14), y, en el período inmediatamente posterior, Ireneo (op. cit., 
Quevedo toma a este personaje del Suplemento (título 3o), que reproduce aquí fielmente a Ravisio; y Fernández Guerra, siguiendo muy de cerca a ese autor, anota: "Sabino, obispo de Heraclea, llamó a todos los cristianos que en el Concilio Niceno anatematizaron a Arrio, idiotas, perezosos y de ingenio enfermizo". Pero el dato es falso. En Nicea sólo hubo cinco obispos que apoyaron a Arrio y se negaron a suscribir las actas: Eusebio de Nicomedia, Maris de Calcedonia, Teonás de Marmórica, Segundo de Ptolemaida, y el mismo obispo de la localidad de Nicea, Teognis. Tres de ellos se retractaron, y sólo Maris y Teognis persistieron, a pesar del anatema. Ningún Sabino, como se ve, figura entre ellos. Más aún: podemos estar seguros de que el dato del Supplementum (copiado de Ravisio) es falso, porque la nómina de los obispos del Concilio de Nicea, escrupulosamente reconstruida ahora en forma casi completa $^{34}$, nos hace saber que el obispo de Heraclea que concurrió a Nicea no fue ningún Sabino, sino cierto Paederos, cuyo nombre aparece en ocho de las fuentes, y en diferentes lenguas. Hubo, sí, un Sabino de Ascalón que concurrió a Nicea, pero en ningún momento figuró entre los disidentes.

Después de Sabino cita Quevedo tres nombres más que toma también del Suplemento: los templarios, Guillermo de Amberes, y la emperatriz Bárbara, que corresponden respectivamente a los títulos 44, $3^{8}$ y 71 . Al parecer, están elegidos al azar. Dice Quevedo.

Después, en miserable lugar, estaban ardiendo por sentencia de Clemente, pontífice máximo que sucedió a Benedicto, los templarios, primero santos en Jerusalem y luego, de puro ricos, idólatras y deshonestos.

¡Y qué fue ver a Guillermo, el hipócrita de Anvers, hecho padre de putas, prefiriendo las rameras a las honestas y la fornicación a la castidad! A los pies de éste yacía Bárbara, mujer del emperador Segismundo, llamando necias a las vírgenes, habiendo hartas. Ella, bárbara como su nombre, servía de emperatriz a los diablos, $y$, no estando harta de delitos, ni aun cansada, decía que moría el alma con el cuerpo, y otras cosas bien dignas de su nombre.

Lo relativo a los templarios está tomado fielmente del texto latino, pero muy abreviado. Dice el Supplementum, entre otras cosas: "Templarii haeretici emerserunt anno 1030... Hierosolymis in tantam sanctitatis opinionem venerunt, ut brevi tempore multas divitias comparaverint... Conflaverunt enim simulachrum... Ne-

V, 33) y Justino Mártir (Diálogo con Trifón el judio, 80-81). Una expresión literaria moderna de este viejo problema teológico es el cuento de Pío Baroja Los herejes milenaristas.

${ }^{34}$ H. Gelzer, H. Hilgenfeld y O. Cuntz, Patrum Nicaenorum nomina, latine, graece, coptice, syriace, arabice, armeniace, Lipsiae, in aedibus G. Teubneri, 1898 . 
fanda masculorum libidine conflagrabant... Devoti sunt flammis sententia Clementis Pontificis Maximi qui Benedicto successit".

Los datos de Quevedo sobre Guillermo de Amberes no corresponden exactamente al Supplementum, de donde los tomó. El texto latino no dice que Guillermo prefiriera "las rameras a las honestas y la fornicación a la castidad", sino que, haciendo hincapié en la pobreza, afirmaba que ésta bastaba para borrar todo pecado, a tal punto que una meretriz pobre es mejor (o más digna) que un beneficiario casto. Añade que Guillermo, simulador e hipócrita, renunció a una prebenda bajo pretexto de pobreza, aunque estaba del todo rendido a la lujuria ${ }^{35}$; no dice la fecha en que vivió ni aporta más datos. Pero alguna información sobre este personaje puede recogerse en los catálogos heresiológicos de los siglos xvi y xvn que lo incluyen. Petreius, por ejemplo, nos informa que vivió a mediados del siglo xirl. Bajo el título "Guilielmus de Sancto amore" dice, entre otras cosas: "Fuit hic infensus Mendicantium religiosorum hostis, promulgans haereses suas sub Alexandro IV, a quo damnatus est per bullam, quae incipit Romanus Pontifex... Docebat enim non licere monachis ex mendicitate vivere, sed ad laborem manuum adstringi, alias nequaquam salvari eos posse..." Como se ve, esta proposición (la necesidad de que los monjes ganaran el sustento con las manos, en lugar de recibir limosnas o prebendas) no difiere esencialmente de una de las más debatidas ideas de Erasmo, tres siglos después.

Y volviendo atrás cuatro hojas del Suplemento nos encontramos con Bárbara (título 38), último de los personajes que Quevedo toma del libro. De aquí provienen los datos concretos: "esposa de Segismundo", "llamando necias a las vírgenes", "decía que el alma moría con el cuerpo" 36 . Bárbara también aparece citada como hereje en el Catálogo de Petreius.

Al llegar a este punto, en que Quevedo deja de usar las fuentes referidas, se advierte un cambio de estilo. Los personajes que siguen son, por orden: Mahoma, Maniqueo y "los herejes de ahora": Calvino, Josefo Scalígero ${ }^{37}$, Lutero, Melanchthon, Teodoro de Beza,

${ }^{35}$ Título 71: "Gvilhermus in vrbe Antwerpiae in hypocrisi et simulatione diutius conversatus. Praebendae beneficium sub praetextu paupertatis dimisit, et tamen luxuriae totus erat deditus. Dicebat autem, sicut rubigem igne, sic omne peccatum paupertate consumi, et ante Dei occulos annullari, meliorem esse publicam meretricem pauperem, quam sit aliquis castus perfectissime continens, dum tamen aliquid in sui retineat subsidium".

so "Barbara, Sigismundi Imperatoris conjunx, stultas dicebat virgines pro Christo passas, quod voluptatis gaudia non gustassent. Dicebat animas cum corporibus interire, nec futuram aliam vitam post hanc, quam vivimus".

${ }^{37}$ Censura Quevedo duramente a "los Scalígeros, hijo y padre" en su Job $(B A A E E$, t. 48 , p. 218 ). Mucho antes había escrito a Justo Lipsio (carta latina de ${ }_{1604}$ ) que tenía la intención, por consejo de don Bernardino Mendoza, de 
Enrico Stéfano y Helio Eóbano Hesso. Todos están suficientemente anotados en la edición de Fernández Guerra. Es casi seguro que estos personajes (presentados sin orden, algunos en tono de burla, y, en general, bastante conocidos en el siglo xvn) no están tomados de ninguna fuente directa ${ }^{38}$.

\section{EL $J O B$ DE QUEVEDO Y LA BIBLIA REGIA}

Al principio de La constancia y paciencia del santo Job de Quevedo leemos (BAAEE, t. 48, p. 214):

La opinión más recibida se contenta con decir que Job antes de la persecución se llamaba Jobab, sin dar alguna causa desta diferencia del nombre... La diferencia es que, llamándose Jobab, se quitaron al nombre las dos letras finales, que son $a b$; y quedó Job $b^{39}$, que significa el afligido, el que llor $a^{40}$. $A B^{*} a b$, que es la partícula que se le quitó, en la lengua siro-caldea ${ }^{41}$ significaba un género de adorno que consta de muchas especies; significa principal, primero en cualquier obra y arte...

Ya se declaran los nombres: en la prosperidad se llamaba Jobab, el doliente, el que lloraba con ornamento, en todo género el primero, el principal, el padre, el maestro. En la persecución... le quitaron el $A B^{*}$, que es el ornamento, principal, primero, padre y maestro, que son las cosas que perdió...

Como el mismo Quevedo da a entender, la identificación de Job con Jobab (biznieto de Esaú, cf. Génesis, 36:33) era común ${ }^{42}$.

escribir un tratado en defensa de Homero, contra las "injurias" de Scalígero (Astrana, Epistolario, Madrid, 1945, p. 7). Si esa obra llegó a escribirse, es, probablemente, el Homeri Achilles aduersus imposturas Maronianas, que menciona Montalbán entre las obras "para sacar a luz" (Para todos, loe. cit.).

${ }_{38}$ Deseo expresar mi reconocimiento al doctor Raimundo Lida, que aportó valiosas sugestiones durante la preparación de las páginas que preceden.

${ }^{3 *}$ Explicación poco acertada. El simple apócope de Jobab no daría Job, pues en hebreo este último nombre empieza con áleph, aquél con yod.

to Para este significado de Job, Quevedo pudo haberse valido del Index Biblicum Joannis Harlemis (incluido en el tomo VI de la Biblia Regia), que da: "Iob: dolens vel gemens, aut ululans".

"1 En el siglo xvn era común denominar "caldeo" al arameo. El término inexacto Parafrastes caldeo (usado repetidamente por Quevedo) se refiere siempre a las antiguas versiones rabínicas del hebreo al arameo, tenidas como texto de gran autoridad para la exégesis bíblica. Sobre la confusión caldeo por arameo, cf. F. Vicouroux, Dictionnaire de la Bible, Paris, 1907, s. v. "Targums". [Las letras $A B^{*}$ que aparecen en este texto son transliteración de las letras hebreas respectivas].

${ }^{42}$ Quevedo la toma de dos autoridades que ha tenido a mano: la Biblia Regia, "Argumentum in librum lob secundum LXX Interpretes", y J. Salian, Annales ecclesiastici Veteris Testamenti (París, 1619), t. 1, pp. 699 ss. 
Pero la explicación que sigue (Jobab pierde su "ornamento" en tiempos de persecución y, al mismo tiempo, pierde la terminación $a b$ de su nombre) parece original de Quevedo.

Este significado ('género de adorno que consta de muchas especies') dado por Quevedo al arameo $a b$ es, sin duda, bastante raro. Supongo que ha de ser más propio del siríaco que del arameo, porque no se halla ni en el antiguo léxico de Schaaf, ni en Buxtorfius, ni en el moderno diccionario talmúdico de Dalman ${ }^{43}$. La fuente directa, que creo haber hallado, es el Dictionarium SyroChaldaicum a Guidone Fabricio Boderiano collecto (Amberes, $1572)^{44}$. Comparemos los textos:

$A B^{*} a b .$. en la lengua sirocaldea significaba un género de adorno que consta de muchas especies; significa principal, primero en cualquier obra y arte.

Es indudable que Quevedo tuvo a mano este Dictionarium SyroChaldaicum, puesto que la obra de Guido Fabricio apareció en el volumen VI de la monumental Biblia Regia o Poliglota de Amberes (sacada a luz por Arias Montano entre 1569 y 1572 , y men. cionada expresamente por Quevedo, p. 217). Y no me cabe duda que Quevedo tuvo a la vista la obra de Arias Montano. Los pasajes latinos que comparamos a continuación son del Argumentum in librum Iob según los Setenta, y el Prologus primus in Job de San Jerónimo, ambos incluidos en la Biblia Regia.

Empero la común opinión es que fue idumeo, con los Setenta, que llamando Ausítide la tierra de Hus, que está en los confines de Idumea y Arabia, en el 36 del Génesis dicen: Primero se llamaba Jobab; luego que se casó con mujer arabisa, engendró un hijo, que se llamó Emmón [sic por Ennón] (p. 213).

${ }^{43}$ Carolus Scha(f, Opus Aramaeum, Lugduni Batavorum, 1686; Jo(nnes Buxtorfius, Lexicum Chaldaicum, Talmudicum et Rabbinicum, Lipsiae, 1885; Gustaf H. Dalman, Aramäisch-neuhebräisches Wörterbuch zu Targum, Talmud und Midrasch, Frankfurt, 1 goı.

${ }^{4+}$ Guido Fabricius Boderianus fue un erudito orientalista francés nacido en 1541. Se especializó en la lengua siriaca, y publicó, entre otras cosas, una versión latina del Peshito. Cf. el Larousse, s. v. "Le Fèvre de la Boderie, Guy".

4: También aquí, las letras $A B^{*}$ son transliteración del hebreo; en el texto de Fabricius, hay un kámets debajo de la áleph, y a continuación van los caracteres siríacos.
In terra quidem habitasse Iob Usitide, in finibus Idumaeae et Arabiae, fertur, et erat ante nomen Jobab. Et accepit uxorem Arabissam, et genuit filium, quem vocavit Ennon. 
Desde el principio del volumen hasta las palabras de Job, en el texto hebreo, está escrito en prosa. Empero desde las palabras de Joi, en que dice: Pereat dies en qua natus sum, et nox, etc., hasta el lugar donde dice: Idcirco ipse me reprehendo et ago poenitentiam in favilla et cinere, son versos hexámetros, dáctilos y spondeos corrientes; y que reciben del idioma de la lengua otros pies, no de las mismas sílabas, sino de los mismos tiempos (p. 217 ).
A principio itaque voluminis us que ad verba lob, apud Hebraeos prosa oratio est. Porro a verbis Iob, in quibus ait: Pereat dies in qua natus sum, et nox in qua dictum est: Conceptus est homo: usque ad eum locum, ubi ante finem voluminis scriptum est: Idcirco ipse me reprehendo et ago poenitentiam in favilla et in cinere: hexametri ver sus sunt, dactylo spondaeoque currentes: et propter linguae idioma, crebro recipientes alios pedes, non earundem syllabarum, sed eorun. dem temporum.

Por sí sola, esta confrontación de textos no sería conclusiva. Podría objetarse que el primer pasaje de Quevedo es, simplemente, una referencia a un texto antiguo reproducido por Arias Montano. En el segundo pasaje, ambos citan a San Jerónimo ${ }^{40}$.

Cierto, pero hay otras partes del Job de Quevedo que no dejan lugar a dudas. Hemos notado que sus repetidas citas del llamado Parafrastes caldeo coinciden siempre, letra por letra, con la versión latina del Targum incluida en la Biblia Regia.

Raúl A. Del Pifro

University of California,

Berkeley.

* Por otra parte, se trataba de un verdadero lugar común. Véase María Rosa Lida de Malkiel, "La métrica de la Biblia: un motivo de Josefo y San Jerónimo en la literatura española", Estudios hispánicos, Homenaje a $A$. $M$. Huntington, Wellesley, Mass., 1952, pp. $335^{-359}$ (sobre Quevedo, pp. 351-352). 